\title{
CONFISSÕES ETNOGRÁFICAS: FRACASSOS NO ACESSO A ORGANIZAÇÕES NO BRASIL
}

\section{Rafael Alcadipani ${ }^{1}$}

\section{Resumo}

O objetivo deste artigo é analisar duas tentativas de acesso para realizar etnografias, em diferentes contextos organizacionais brasileiros: um importante jornal e uma força de segurança militar. Como resultados, aponto que fazer etnografia pode ser danoso para a carreira do pesquisador em uma academia dominada pelo produtivismo. Ainda, aponto que a etnografia organizacional impõe desafios ao pesquisador. Todavia, é a melhor forma de conhecer as organizações como elas acontecem, com rigor de detalhes e minúcias.

Palavras-chave: Etnografia; Pesquisa Organizacional; Acesso ao Campo.

\section{CONFESSIONS ETHNOGRAPHIC: FAILURES IN ACCESS TO ORGANIZATIONS IN BRAZIL}

\begin{abstract}
The purpose of this article is to analyze two access attempts to conduct ethnographic research in different Brazilian organizational contexts: a major newspaper and a military security force. As a result, it points to do ethnography can be harmful to the researcher's career in a gym dominated by high productivity. Still, it points out that organizational ethnography poses challenges to researchers. However, it is best to know the organizations as they happen, with details of accuracy and detail.
\end{abstract}

Keywords: Ethnography; Organizational Research; Access to Field.

${ }^{1}$ PhD em Management Sciences. Professor Adjunto da EAESP/FGV. Email: Rafael.alcadipani@fgv.br Revista Brasileira de Estudos Organizacionais - v. 1. n. 1, p. 64-87, jun. 2014, eISSN: 2447-4851 Sociedade Brasileira de Estudos Organizacionais 


\section{Introdução}

Muito embora discussões sobre o acesso ao campo para realizar pesquisas estejam presentes em estudos qualitativos há algum tempo (e.x.: BROWN et al., 1976; GRAY, 1980; FELDMAN et al., 2002; HARRINGTON, 2003; CROWLEY, 2007), análises e discussões sobre a negociação de acesso para pesquisa estão pouco presentes nos Estudos de Administração e Organizações (BRUNI, 2006). E, quando esses debates ocorrem, tendem a ficar "nos bastidores" (GELLNER e HIRSCH, 2001), relegados a apêndices curtos ou prefácios (ver KUNDA, 1992). Tal fato chama a atenção uma vez que o processo de negociação de acesso para a realização de pesquisas é, reconhecidamente difícil, mesmo em contextos não organizacionais, como, por exemplo, no caso de antropólogos famosos, como Boas e Malinowski, que terminaram por não obter acesso a campos específicos durante suas carreiras (MORRILL et al., 1999).

De fato, o acesso tem sido uma preocupação em todos os tipos de pesquisa de campo (JOHNSON, 1975) e pode estar cercado por dificuldades específicas em pesquisas envolvendo organizações. Nesse caso, a negociação de acesso pode ser ainda mais dificultada em virtude da relutância de muitas organizações em abrir as suas portas, temerosas de que seus "segredos" se tornem públicos (BRYMAN, 1988; BUCHANAN et al., 1988; SMITH, 1997, 2000; ALVESSON e DEETZ, 2000; GELLNER e HIRSCH, 2001; BRUNI, 2006b). Os responsáveis por manter os segredos das organizações, como os gestores e executivos, são aqueles que decidem quem pode e quem não pode entrar no seu interior. Esses, verdadeiros "leões de chácara" organizacionais, tendem a ficar preocupados com a possibilidade de que relatórios de pesquisa exponham as práticas da empresa para o público em geral, ou, até mesmo, sejam utilizados em processos judiciais contra a organização que representam (SMITH, 2000). Dessa forma, a tendência indica que, quanto mais tempo o pesquisador pretender ficar na organização e quanto mais sensível for o tema da pesquisa, mais dificuldade esse terá para conseguir o tão necessário acesso, sem o qual a pesquisa não poderá ser realizada. Tal situação é particularmente delicada em estudos etnográficos que, em geral, devem envolver um longo período do tempo na organização a ser pesquisada (BATE, 1997).

O objetivo deste artigo é analisar duas tentativas de acesso para realizar etnografias, em diferentes contextos organizacionais brasileiros: um importante jornal e uma força de segurança militar. Nos dois casos, as pesquisas fracassaram em virtude de dificuldades de acessar informações no campo. Por meio de uma narrativa confessional (VAN MAANEN, 1988), irei discutir que aspectos ligados à construção da identidade do pesquisador durante a pesquisa e o contexto da organização a ser 
estudada podem agir para impossibilitar a plena realização da pesquisa etnográfica organizacional. Para tanto, na próxima seção, analiso a etnografia em análise das organizações e em estudos da administração e, ainda, de que modo a literatura da área trata a questão do acesso ao campo. Em seguida, apresento a abordagem metodológica do artigo para, então, descrever as duas tentativas de acesso nas duas organizações mencionadas.

Antes das conclusões, discuto de que maneira as tentativas de se conseguir acesso para a realização de pesquisas etnográficas dependem do contexto social em que a organização está inserida, um aspecto desconsiderado pela literatura. Discuto, ainda, de que modo as dinâmicas de campo terminaram por constituir identidades específicas dos etnógrafos em ação no campo, e chamo a atenção para o fato de que tais identidades facilitam ou dificultam a realização da pesquisa, indicando que o acesso formal é apenas uma das etapas para se conseguir coletar informações no campo. Ao fazer isso, procuro contribuir para discussões a respeito das práticas de acesso ao campo de pesquisa em organizações no Brasil, uma vez que a maioria da literatura disponível a respeito do assunto é escrita em inglês e trata do assunto, exclusivamente, em âmbito internacional. Além disso, no Brasil, temos o costume de apresentar pesquisas que representam os casos de sucesso e não revelamos nossos fracassos como pesquisadores, deixando de apreender com eles. Por fim, este artigo contribui ao discutir que o acesso não depende apenas das habilidades do pesquisador, mas, também, de construções identitárias e do contexto em que a organização está inserida, dois aspectos não abordados pela literatura.

\section{Etnografia, Análise das Organizações e a Questão do Acesso}

O Brasil possui uma tradição de estudos etnográficos em Administração analisando temas que variam da cultura de peritos criminais (ex.: CAVEDON, 2010), passando pela questão do embodiement (FLORES PEREIRA, 2007) até micropolíticas de práticas cotidianas em organizações circenses (OLIVEIRA; CAVEDON, 2013). Assim como no cenário internacional, discussões a respeito da prática da pesquisa etnográfica ainda são incipientes na área no país (para exceções veja: CAVEDON; FLORES PEREIRA, 2009; TURETA; ALCADIPANI, 2011), havendo um predomínio de discussões genéricas a respeito da abordagem etnográfica (MASCARENHAS, 2002; VIEIRA, 2005).

Etnografia pode ser definida de diferentes maneiras: um determinado tipo de atividade de campo, um paradigma intelectual ou um estilo de narrativa (BATE, 1997). Esse tipo de estudo "produz dados empíricos sobre as vidas de pessoas em uma situação específica" (SPRADLEY, 1979, 
p. 13) e envolve "o etnógrafo participando, aberta ou veladamente, em atividades das pessoas por um período prolongado de tempo, observando o que acontece, ouvindo o que é dito, fazendo perguntas" (HAMMERSLEY; ATKINSON, 1995, p. 1).

A abordagem etnográfica tem uma presença importante e distintiva no campo da Administração e Organizações, onde tal abordagem tem sido vital para o desenvolvimento de uma compreensão mais profunda sobre o mundo da gestão, das organizações e do trabalho (VAN MAANEN, 1979; BATE, 1997; SMITH, 2000). Os usos da etnografia como uma estratégia de pesquisa na área têm levado a debates epistemológicos a respeito do papel da linguagem, das possibilidades de representação e da possibilidade de se produzir uma verdade única por meio de etnografias (JONES, 2000). Menos frequente, no entanto, são discussões a respeito da prática da pesquisa etnográfica. Especialistas têm dividido etnografia em duas fases diferentes: uma mais reflexiva, quando os dados são analisados e os textos acadêmicos são produzidos; e outra fase mais prática, essa relacionada à coleta dos dados (VAN MAANEN, 1995; DENZIN, 1997; BRYMAN, 2001). Nesse contexto, há uma tendência de concentrar os estudos e as discussões a respeito dos momentos reflexivos do estudo etnográfico, tais como a análise de material empírico ou como escrever relatos etnográficos. Em tais discussões, debates sobre ontologia, epistemologia e dilemas éticos emergem e são devidamente desenvolvidos. Todavia, tais discussões são realizadas em detrimento dos momentos práticos da etnografia, os quais são vistos como não problemáticos e que devem ser tratados pragmaticamente (FETTERMAN, 1989; VAN MAANEN, 1995; BRYMAN, 2001). Por exemplo, embora a escrita de notas de campo tenha atraído a atenção na pesquisa etnográfica, tal aspecto tende a ser tratado como uma praticidade sobre a qual estudiosos experientes podem aconselhar pesquisadores iniciantes em como fazer (ver EMERSON et al., 1995). Até mesmo críticas pós-modernas não têm desafiado ou questionado aspectos da pesquisa etnográfica considerados práticos (VAN MAANEN, 1995; MARCUS, 1997).

A questão do acesso tende a ser tratada como uma das etapas práticas e não reflexivas de se fazer etnografia. É uma questão vista como quase não problemática. A maioria do que foi escrito sobre o tema encontra-se publicada em livros didáticos que buscam fornecer algumas dicas a respeito de como solucionar o problema do acesso (BRYMAN, 1988). Especificamente, tais textos oferecem conselhos sobre estratégias destinadas a garantir o acesso ao campo da pesquisa. Não faltam estratégias propaladas pelos textos didáticos metodológicos que incluem o gerenciamento de impressão do pesquisador perante a organização (JOHNSON, 1975; AGAR, 1980; FETTERMAN, 1989; SILVERMAN, 1999; HAMMERSLEY e ATKINSON, 1995; FELDMAN et al., 2002), a obtenção "bottom-up" de acesso (SILVERMAN, 1999), e a não realização de julgamentos a respeito de fatos que ocorrem no campo, em especial, 
durante o início do estudo (HAMMERSLEY; ATKINSON, 1995; SILVERMAN, 1999). Há ainda aqueles que apontam que acesso pode ser conseguido por meio do estabelecimento de um contrato formal e com validade legal (SILVERMAN, 1999) e pela utilização de redes pessoais e institucionais do pesquisador para entrar na organização desejada (BRYMAN, 1988; HAMMERSLEY e ATKINSON, 1995; GILL e JOHNSON, 2002). Encontramos na literatura aqueles que defendem ser importante não deixar tão explícito o que se pretende pesquisar, especialmente, quando se trata de assuntos polêmicos (JOHNSON, 1975; HAMMERSLEY e ATKINSON, 1995; ALVESSON e DEETZ, 2000); ganhar acesso progressivamente sem deixar explícito que se busca fazer uma etnografia (JOHNSON, 1975); desenvolver e nutrir relacionamentos com atores importantes do campo (BRYMAN, 1988; FETTERMAN, 1989; FELDMAN et al., 2002); realizar uma gestão eficaz dos "leões de chácara organizacionais" (MORRILL et al., 1999); conseguir o patrocínio de um estudioso sênior para obter acesso, tornando-se um agente de mudança na organização pesquisada (GUMMESSON, 2000); e realizar pesquisas sem que a organização saiba (ALVESSON; DEETZ, 2000), algo bastante controverso.

Além disso, argumenta-se que o acesso pode ser facilitado quando o pesquisador oferece algum tipo de reciprocidade à organização estudada, como, por exemplo, seções oferecendo feedback originado dos resultados da pesquisa ou até mesmo treinamento para funcionários da organização pesquisada. Tal reciprocidade não é apenas apresentada como uma estratégia de acesso, mas, também, como uma boa prática de pesquisa (BROWN et al., 1976; BRYMAN, 1988; HAMMERSLEY e ATKINSON, 1995; SILVERMAN, 1999; RAM, 2000; GILL; JOHNSON, 2002), ou até mesmo que se trata de uma obrigação ética (BELL; BRYMAN, 2006). Particularmente, eu discordo desse último aspecto, uma vez que o compromisso do pesquisador deve ser, antes de tudo, com a sociedade e com a geração de conhecimento para a sociedade, e não apenas para a organização. Quando o retorno para a organização é feito a respeito de pesquisas que tratam de temas delicados, como resistência, sabotagem, controle, ideologia e poder, somente para citar alguns, pode haver o prejuízo de atores organizacionais, especialmente, daqueles que estão na parte mais baixa da pirâmide organizacional. Eu compreendo a pesquisa como um bem público e não como algo privado. Por isso, dar o retorno da pesquisa para a organização pesquisada deve ser uma decisão única e exclusiva do pesquisador, que deve avaliar tal possibilidade dependendo do tipo de estudo que está realizando.

Uma vez que o acesso às organizações é concedido pelos executivos, o desafio, de acordo com a literatura em metodologia de pesquisa na área de administração, é convertido em um problema de "gestão" do processo de trabalho de campo e das relações com os informantes no dia a dia da organização (HAMMERSLEY; ATKINSON, 1995; SILVERMAN, 1999; 
GILL; JOHNSON, 2002; FELDMAN et al., 2002). Até mesmo uma abordagem empresarial e funcionalista foi defendida para lidar com as questões cotidianas e contingenciais do trabalho de campo (RAM, 2000). As pressões resultantes do perigo percebido de perder acesso formal, raramente, são abordadas de forma explícita, bem como casos em que o acesso foi tentado, porém não foi possível realizar a pesquisa.

De acordo com Alcadipani e Hodgson (2009), o consenso na literatura a respeito da aquisição e manutenção de acesso em pesquisa etnográfica em organizações é que a implantação bem-sucedida de um conjunto correto de estratégias e gestão de certos aspectos da relação do pesquisador com o campo acabará por conceder e manter o acesso para o pesquisador. Por conseguinte, o acesso é retratado como uma tarefa neutra e operacional, com pouca ou nenhuma consequência ética, além dos debates a respeito da validade moral de empregar estratégias de pesquisa em que a organização não é informada oficialmente a respeito da realização do estudo (ex.: BULMER, 1982).

Para Alcadipani e Hodgson (2009), retratar o acesso da maneira descrita acima reflete uma suposição de que o pesquisador tem controle significativo sobre o campo, atribuindo agência em demasia para o pesquisador e muito pouco para o pesquisado. Isso reforça a ideia de sujeitos de pesquisa sob o controle do pesquisador que possua as qualidades e habilidades gerenciais corretas. Tais discussões a respeito de acesso parecem assumir que as organizações permanecem estáveis durante e após a negociação de acesso, descrevendo as organizações como entidades coesas com uma vontade unificada (ou seja, para permitir ou para negar o acesso). Aliás, esse tipo de orientação parece ter implícita a possibilidade da utilização de uma racionalidade exclusivamente instrumental no campo da pesquisa, algo que deve colocar dilemas para pesquisadores, em especial, para aqueles que seguem uma abordagem crítica, a qual busca desafiar e questionar a razão instrumental em ação.

Com o intuito de mostrar as nuances relacionadas com a aquisição e manutenção do acesso em pesquisa etnográfica em organizações, no restante deste artigo, pretendo discutir dois casos relacionados à questão do acesso ao campo de pesquisa. Ao fazer isso, pretendo contribuir para discussões a respeito das práticas de acesso ao campo no Brasil, uma vez que a literatura tende a tratar de contextos diferentes do nosso (ex.: ALCADIPANI; HODGSON, 2009).

\section{Metodologia}

Com o intuito de focar em tentativas para conseguir acesso para pesquisa, eu utilizo, neste artigo, uma narrativa confessional (VAN MAANEN, 1988). A ideia deste tipo de narrativa é desmistificar a prática de campo mostrando como a pesquisa é feita na prática. É, ainda, relatada em primeira pessoa e mostra o ponto de vista do pesquisador. Durante o 
processo para conseguir acesso a fim de realizar cada uma das pesquisas descritas abaixo, eu elaborei um diário de campo, desde o primeiro contato para conseguir entrar na organização a ser pesquisada. Os diferentes diários de campo foram produzidos nos últimos anos, durante todas às vezes que eu tentei acesso para uma nova pesquisa etnográfica em uma organização. As tentativas de acesso que eu descreverei a seguir ocorreram em um jornal brasileiro de grande circulação e em uma Força de Segurança Militar Brasileira (FSMB).

A tentativa de acesso ao jornal foi feita em 2009 e o acesso formal foi conseguido, porém, a pesquisa fracassou, conforme descreverei abaixo, devido a outro aspecto associado a conseguir coletar dados no campo. No caso da FSMB, o acesso foi formalmente franqueado em 2012, mas, informalmente, restringido, o que também levou ao fracasso do estudo. Além disso, a situação do contexto social na época em que o acesso foi conseguido indicava, claramente, que a pesquisa deveria ser abortada. Os nomes das organizações serão mantidos em sigilo, bem como de todas as pessoas envolvidas no processo, a fim de garantir a privacidade das pessoas e a confidencialidade das organizações. Os eventuais nomes utilizados, tanto das pessoas como das organizações, não correspondem aos nomes verdadeiros. Nas duas organizações, eu me apresentei e sempre que possível me reforcei como professor e pesquisador. Nos dois casos, eu pedi autorização formal para realizar a pesquisa.

Eu separei cada uma das histórias relativas ao acesso e as codifiquei. Seguindo os conselhos de Spradley (1979), li atentamente as descrições das tentativas de acesso e busquei encontrar temas convergentes dentro das histórias de cada uma das tentativas e, também, entre as diferentes tentativas. Repeti o mesmo processo por três vezes. Ao ler o material, ficou claro que, em cada uma das situações, o campo me constitui como um indivíduo dotado de uma identidade específica que facilitou ou dificultou, enormemente, minha coleta de dados no campo. Na sequência, descrevo cada uma dessas narrativas de acesso.

\section{Fracassos de Acesso a Informações para a Realização de Etnografias Organizacionais}

Nesta seção, descrevo, em tom confessional, duas experiências que vivenciei na tentativa de conseguir acesso para fazer pesquisa etnográfica no Brasil. Em cada um dos relatos, minha identidade na organização em que eu gostaria de entrar foi constituída de maneira diferente, dependendo das circunstâncias do momento e da minha interação com os agentes no campo. Reconheço a existência de uma vasta literatura a respeito do tema identidade em organizações. Todavia, meu objetivo neste texto é discutir questões ligadas à identidade do pesquisador em contato com o campo de pesquisa, uma discussão menos aprofundada no campo dos estudos da Administração e das Organizações. Wax (1979) foi um dos 
pioneiros a tratar dessa questão na antropologia, ao destacar que "É evidente que aspectos da identidade do pesquisador ligados à gênero, à idade, à raça, à prestígio e a diferentes questões ligadas à etnia do pesquisador podem limitar ou determinar aquilo que o pesquisador pode conseguir no campo" (WAX, 1979, p. 513) e que, no campo, nossa identidade é exposta e até mesmo amplificada. Wax (1979) estava preocupado em associar a demografia do pesquisador com a dos pesquisados para conseguir aumentar a eficiência na coleta de dados. Visões contemporâneas percebem a identidade das pessoas em contexto organizacional como fluídas e construídas socialmente em cada situação organizacional (ex.: PULLEN e LINSTEAD, 2005). É a partir dessa visão sobre identidade que irei analisar os dois casos que eu apresento abaixo.

\section{O Playboy e a Desigualdade Social}

Antes de realizar a tentativa de fazer uma etnografia em um jornal no Brasil, minha última pesquisa foi realizada no parque gráfico de um jornal localizado no exterior. Lá, passei cerca de nove meses dentro da organização, onde apenas consegui o acesso após 10 meses de idas e vindas em contato com diferentes tomadores de decisão no jornal e falando com diferentes pessoas. Além disso, minha pretensão era realizar a pesquisa em uma redação para entender práticas de resistência no contexto da produção de notícias. Eu consegui o acesso na redação em um primeiro momento, mas ele foi retirado após algumas semanas, pois o local iria passar por uma completa reestruturação com a demissão de inúmeros funcionários. O presidente do jornal, ao solicitar que eu não mais fosse fazer observações na organização, foi categórico ao afirmar que ele não poderia permitir que alguém testemunhasse as mudanças, dado o custo humano que elas incorreriam. Esse processo foi emocionalmente estressante, passei várias noites sem dormir e fiquei com grande receio de perder o acesso à gráfica, o que seria crucial para a realização da pesquisa que, naquele momento de minha vida, era extremamente importante para minha carreira e para mim.

Considerando essa experiência, imaginava que conseguir acesso ao jornal no Brasil para fazer uma pesquisa etnográfica seria muito difícil. Com a ideia de realizar o estudo, comecei a perguntar para os meus contatos se eles conheciam alguém que trabalhava no jornal que eu escolhera. Eu acreditava que ter um conhecido dentro da empresa poderia me abrir as portas para a pesquisa. Após conversas com vários amigos e colegas, constatei que ninguém tinha conhecidos no local. Em certo dia, pensei que eu poderia tentar o óbvio, ou seja, ligar para a central telefônica do jornal, pedir para falar com o Diretor que cuidava da impressão do periódico e falar a respeito dos meus objetivos e das minhas intenções de pesquisa. Lembrei-me de um amigo que sempre me dizia que, muitas vezes, esquecemos que o caminho óbvio pode ser o mais fácil, e não o 
tentamos por parecer óbvio demais. Foi o que fiz: liguei para a central telefônica do jornal e fui informado pela telefonista que havia um Diretor Industrial na organização. Pedi para que minha ligação fosse transferida para esse diretor e fui atendido por sua secretária. Informei ser professor de uma instituição de ensino superior considerada de prestígio no país, e que havia feito uma pesquisa dentro de uma das maiores gráficas de jornal da Europa, pertencentes a um dos maiores grupos de mídia do mundo. A minha fala soou um pouco como "Você Sabe com Quem Está falando?", mas, de maneira bastante sutil. Ao citar o jornal europeu, também joguei um pouco com a valorização do estrangeiro por parte dos brasileiros. Ela anotou, com muito interesse, meus dados. Para minha total surpresa, em menos de meia hora, o diretor de produção me telefonou e, muito simpático, convidou-me para uma reunião, a qual realizou-se na semana seguinte.

A reunião transcorreu muito bem. Expliquei minhas intensões com a pesquisa. O diretor, naquele momento, demonstrou gostar muito da ideia e, após conversar com o gerente de produção, garantiu que eu teria acesso total e irrestrito na organização. $\mathrm{O}$ diretor disse, por diversas vezes, que ele respeitava muito a minha instituição de ensino e que gostaria que eu ensinasse a eles como os europeus faziam com questões relativas à qualidade. Parecia que o diretor percebera a pesquisa como uma forma de conseguir uma espécie de consultoria gratuita. Eu não desmenti nem confirmei o que acreditava ser sua percepção a respeito do benefício da pesquisa, afinal, não fui perguntado diretamente. Claramente, a reputação da instituição em que trabalho e o fato de eu ter informações a respeito de como funcionava uma gráfica no exterior contaram muitos pontos a meu favor. Tendo sido acertado que os supervisores de linha iriam realizar minha introdução aos funcionários, recebi um crachá de acesso na empresa e obtive permissão para entrar e sair quando bem que me conviesse. Ainda, foi-me designado um local no estacionamento para parar meu carro quando fosse à fábrica, ao lado do estacionamento dos executivos da empresa.

No dia agendado, compareci ao jornal no turno da noite. Lá, conversei brevemente com o supervisor, que chamou todos os trabalhadores para explicar quem eu era. Também fui chamado a me apresentar. Minha apresentação foi seguida por um silêncio ensurdecedor. Todos, sem exceção, olhavam para mim com olhar de grande desconfiança. O clima estava tenso. Os rostos dos trabalhadores permaneciam fechados. Fui para uma das máquinas acompanhar o trabalho que era executado. Conversei com o primeiro oficial da máquina, o líder da equipe, que foi bastante gentil. Na primeira noite, conversei majoritariamente com ele. Diferentemente do diretor, ele mal reconhecia a instituição de ensino de onde eu vinha e o jornal europeu supostamente famoso. Conversamos muito sobre futebol e demais amenidades. Comecei a notar que eu e os operários morávamos em locais praticamente opostos da cidade (centro e 
periferia), tínhamos diferente grau de instrução, frequentávamos locais totalmente distintos, circulávamos por transportes diferentes, tínhamos acesso a bens culturais totalmente diferentes, nossas experiências com a violência urbana eram diferentes, etc. Era como se eu e eles vivêssemos em cidades totalmente distintas. Percebia estar passando por uma barreira muito maior do que a portaria da empresa: a barreira das classes sociais no Brasil.

Conforme a pesquisa se desenvolveu, eu fui ficando mais próximo dos operários que eram, em geral, extremamente receptivos a uma primeira impressão. Conversávamos de amenidades, assuntos do cotidiano, futebol e questões familiares. Alguns deles pediam ajuda com tarefas da escola, já que sabiam que eu era professor. Porém, cada vez mais ficava claro que nossos mundos eram muito diferentes. Eles, na brincadeira, chamavamme de "playboy". O que parecia uma brincadeira, conforme o tempo passou, foi se configurando como a afirmação de uma barreira entre nós. Eles sempre me diziam que tudo estava certo, que não havia conflitos na empresa e que a organização era um excelente empregador. Qualquer pergunta minha a respeito da organização era respondida, mais ou menos, nos mesmos termos. Eles me repetiam sempre o discurso oficial, aquilo que os gestores esperavam. Fiquei muito próximo de um dos operários que me disse: "Sabe, mano, o bicho pega na fábrica. É foda pra $c^{* * * "}$. Quando eu pedi para ele me detalhar mais, ele me disse: "O patrão, tu é amigo dos homi. Os supervisor fala com você com respeito, fica preocupado com o que cê tá vendo. Cê acha que eu vou dar a letra pro cê? Dá não. Tu para o carro no estacionamento dos patrão, tô fora, mano!".

Alguns deles respondiam às minhas perguntas e insinuações com monossílabos, e outros chegavam a ser diretos e agressivos. Eles jamais falavam de coisas delicadas a respeito do trabalho na minha frente. Um operário antigo, certa vez, me disse: "o seu $\mathrm{m}^{* * *}$, tu é playboy e eu não falo com playboy". Eu estava longe de usar roupas caras ou com marca exposta no chão de fábrica. Sempre ia com roupas de cor sólida e calça escura. Além disso, jamais ficava "contanto vantagem" ou descrevendo coisas que pudessem reforçar a distância social. Mesmo assim, a imagem de "playboy" estava presente. Certa vez, assistíamos a um programa de TV, quando mostrou uma mesa de jantar com vários talheres. Um dos operários me perguntou: “ô mano, na tua casa a mesa é assim?", demonstrando que eles tinham uma imagem ao meu respeito bastante estereotipada. Um operário que dizia ser pai de santo me disse que a "guia" dele havia dito para ele não confiar em mim. Ele era uma espécie de liderança no campo e eu tinha certeza que ele falava para os demais não terem confiança em mim.

Por mais que eu tentasse conseguir mais informações a respeito do que acontecia na fábrica, os operários sempre eram muito reticentes ao responder minhas perguntas. Escutei inúmeros comentários de que eu conhecia os gerentes e diretores e que eu não era confiável. De fato, eu andava, gesticulava e falava de uma maneira muito diferente dos 
operários, por mais que tentasse, muitas vezes, diminuir a distância. Se eu tentava imitá-los no falar, escutava: "tá me tirando?". Um professor, que fizera uma pesquisa na Europa e que parava o carro no estacionamento dos executivos. Alguém que era muito próximo no linguajar e hábitos dos gestores da empresa.

O resultado disso foi que eu não consegui romper a barreira com eles e, após quatro meses, decidi sair do campo e deixar a pesquisa. Meu foco de investigação eram as práticas de controle e resistência, e eu percebi que eu era um objeto de resistência por parte dos operários. Tratava-se de uma resistência um pouco mais velada, de aparência muito gentil e afável, mas muito difícil de ser transposta. Algumas vezes, ela se tornava agressiva. Notei que a questão da desigualdade social no Brasil está imersa na nossa forma de falar, expressar e caminhar. Eu poderia ter seguido no campo, mas não via nenhuma possibilidade de romper com a barreira que os operários me colocaram e percebi, então, que seria muito difícil ser percebido, por eles, como um igual e, assim, ter conversas mais verdadeiras com eles. Possivelmente, eu poderia ter insistido mais. Todavia, eu estava também sem paciência, pois fizera um longo estudo de campo há pouco tempo, havia acabado um trabalho acadêmico de vulto e não havia ainda pensado que voltar ao campo poderia ser penoso para mim. A junção entre a resistência dos operários e a minha qualificação como "playboy", as barreiras da desigualdade social e a minha falta de paciência acabaram por fazer com que a pesquisa não desse certo. Discorro a respeito de uma segunda tentativa de acesso, a seguir.

\section{O Não Cientista e a "Guerra Urbana"}

Sempre tive interesse em realizar uma pesquisa etnográfica em uma organização relacionada com a segurança pública no Brasil. Sendo o Brasil um dos países mais violentos do mundo, estudos sobre o cotidiano de forças de segurança são fundamentais para compreender tais organizações e as características da nossa violência.

Por um acaso, descobri que um conhecido meu, o Antônio, tinha contato direto e institucional com um dos líderes de uma importante força de segurança militar brasileira. Comentei com o Antônio a respeito da minha ideia de pesquisa e ele me disse que falaria com o comandante da FSMB a respeito de meu interesse em estudar a organização. Ele me disse ter um contato frequente com o comandante em questão e que, ao longo da sua relação de anos com a FSMB, ele sentia que essa seria uma organização bastante formal e não muito aberta e receptiva para quem é de fora. Alguns dias após a minha conversa, Antônio pediu que lhe desse um cartão de visitas profissional para entregar ao comandante. Passado algum tempo, ele me trouxe o cartão do comandante que gostara da ideia da pesquisa e estava disposto a conversar comigo. $\mathrm{O}$ comandante havia sugerido que eu enviasse um correio eletrônico para ele. De bate e pronto, 
encaminhei um correio ao comandante, cujo conteúdo foi elaborado com a ajuda de Antônio, que sugeriu várias coisas, como, por exemplo, que eu jamais utilizasse a palavra investigação como sinônimo de pesquisa, pois a FSMB teme muito ser analisada, avaliada e julgada. Algumas horas depois, o comandante respondeu a minha mensagem pedindo para que eu ligasse para um de seus assessores para marcarmos uma reunião. $\mathrm{Na}$ minha primeira tentativa, o assessor não estava. Deixei recado.

Alguns dias depois, uma aluna que utiliza a minha sala para atividades acadêmicas veio me dizer "Viu? O que você está aprontando? Ligou aqui uma pessoa da FSMB e pediu para retornar a ligação". A fala da aluna é interessante ao mostrar que não lidamos com as forças de segurança no Brasil, ao menos que algo de errado tenha acontecido, o que sinaliza para a distância entre essas e os cidadãos. Chamou-me a atenção, também, o fato de que quem me ligou era uma pessoa que se identificou como soldado Mariana. Retornei a ligação. Ao falar com a soldado, ela foi extremamente educada e me transferiu para o major Diogo que, ao saber do que se tratava, me transferiu para o coronel Adolfo, o responsável por marcar o horário na agenda do comandante. Também me chamou atenção o uso da patente da pessoa antes do nome, algo que reforça a hierarquia presente na instituição.

Todas as pessoas próximas para quem eu disse que iria ter uma reunião de pesquisa na FSMB reagiram de maneira bastante refratária. Alguns diziam: "mas porque você vai se meter com esta gente"; outros demonstravam bastante preocupação com a minha segurança pessoal ao me envolver com a organização. A essa altura, já estava bastante claro para mim que as pessoas não se relacionam bem com as forças de segurança pública no Brasil e, ainda, que há extrema desconfiança a respeito delas, algo que eu, intuitivamente, já sabia, por minha condição de cidadão. Antes de eu ir para a reunião, conversei com amigos do Judiciário a respeito de qual tipo de indumentária deveria utilizar. A voz uníssona foi de que eu deveria ir sem barba, de terno e gravata, pois inspiraria autoridade e respeito, algo importante em uma organização altamente hierarquizada. Além disso, para essa reunião, levei uma proposta de pesquisa impressa em arquivo de apresentação. A ideia da pesquisa era acompanhar o dia a dia de alguma unidade da FSMB para compreender as práticas de gestão dentro da instituição, uma proposta bastante aberta. Na apresentação, inclui que iria fazer um comparativo com uma pesquisa similar desenvolvida por uma colega pesquisadora na Austrália e outra no Reino Unido, acreditando que poderia ser útil para conseguir o acesso. Implicitamente, eu usava aqui a estratégia que foi útil no caso do jornal. Os objetivos da pesquisa eram abertos, o que não poderia ser diferente em se tratando de uma proposta de etnografia fundamentada em uma epistemologia pós-estruturalista.

No dia marcado, trajando terno e gravata, com a barba feita, compareci à reunião agendada com o comandante da tropa, no Quartel 
General da FSMB. Logo na recepção, fiquei esperando por alguns minutos pelo fato de que não haviam encontrado o registro da minha reunião na agenda do comandante. Achei estranho. Na recepção, observei um entra e sai de militares de todas as patentes. Alguns batiam continência ao passar por outros que ali circulavam. Os móveis da recepção não combinavam com o tipo de sala, que era mais rústica, enquanto os móveis eram do estilo de escritório. Uma TV de LED grande fazia o ambiente ainda mais destoante. Desde que entrara no Quartel, eu só vi pessoas uniformizadas. O fato de eu estar sem uniforme deixava claro que eu era um "estranho no ninho". Fui levado até o último andar do quartel por um jovem cabo. Lá, fui entregue a outro militar, dessa vez, uma mulher. Ela me pediu para que eu esperasse em um salão ao lado da sala dela. Era um salão gigantesco e imponente, com quadros nas paredes da figura de militares e com sofás de couro grandiosos. O salão impunha muito respeito e dava uma sensação de estar em um lugar bastante poderoso. Eu me sentia minúsculo dentro da suntuosidade do ambiente.

Fui chamado e apresentado ao subcomandante Aroldo, que tem a patente de Coronel. Muito afável, ele comentava a respeito da importância do estudo nos dias de hoje. Também elogiou a minha instituição, e disse que o sonho dele era que sua filha lá estudasse. Falamos sobre diversas amenidades. Eu acreditava que o comandante ainda viria para a reunião e estava apenas na antessala. Demorou para eu perceber que seria atendido por Aroldo. Só notei isso quando o tempo passou e o subcomandante me perguntou a respeito da pesquisa. Ele pediu para que fossem chamados alguns coronéis para a nossa conversa. Em todos os momentos em que era possível, foi dito: "você sabe que somos muito abertos". No total, a conversa prosseguiu com seis coronéis na sala mais o Aroldo. Quando me dei conta, estava em uma sala rodeada por homens de uniforme cheios de brasões e estrelas, armados e que não se mostravam nem um pouco amistosos. Um deles, de repente, e de forma bastante áspera, perguntoume: "você disse que é pesquisador e professor, não é isso? Mas, para você, a prática serve para alguma coisa?". Não entendi ao certo o tom agressivo e desafiador da pergunta. Algumas outras perguntas seguiram no mesmo tom. Antes de me perguntarem, todos solicitavam ao Aroldo: "comandante, posso me pronunciar?".

A proposta de realizar observações dentro de uma unidade da FSMB não pareceu gerar entusiasmo entre os presentes. Os militares queriam saber, exatamente, quais eram as minhas hipóteses, meus instrumentos de coleta de dados e meus procedimentos de análise. Eles tentavam usar uma regra quantitativa para analisar uma proposta qualitativa e pareciam muito frustrados com a ausência de uma proposta mais estruturada. Ainda, eles mostraram apreensão em não saber quais seriam os resultados da pesquisa. Eu rebatia dizendo que, nesse tipo de pesquisa, não se tem como saber de antemão o que iremos encontrar. A pressão foi tanta, no sentido de ter uma proposta estruturada, que em determinado momento 
eu respondi: "Olha, se os senhores querem uma proposta bem estruturadinha, eu consigo fazer facilmente, mas quando eu for para o campo, isso vai mudar, com certeza". Minhas respostam não agradavam e o clima ficava cada vez mais tenso.

Então, os militares passaram a fazer perguntas do tipo: "mas, me conta uma coisa, o que você conhece da FSBM? Você já estudou o que fazemos?". Em todo o tempo, os coronéis falavam a respeito das peculiaridades do trabalho realizado pelos militares e tentavam mostrar uma organização que lidava com muitas complexidades. Um deles disse: "aqui, nós atendemos desde chamados para verificar discos voadores até ações de resgate altamente complexas". Quando tentei explicar que minha proposta era diferente das pesquisas quantitativas e tradicionais, um deles me disse: "quer dizer, então, que isso aí que você faz não é ciência?". O clima de tensão apenas aumentava e eles estavam clara e nitidamente me testando. Contudo, eu não percebi isso na hora, dado ao nervoso de estar rodeado por homens de uniforme e armados, e acabei respondendo, também de maneira agressiva, a uma pergunta mais áspera. Eu disse a um dos coronéis: "O senhor é doutor para falar de ciência e de como se realizar uma pesquisa? Onde o senhor fez o seu doutorado? Eu sei o que faço e o que estou fazendo, agora os senhores precisam ver se esta proposta interessa aos senhores. O que eu tenho a oferecer aí está". Já se ia quase uma hora de reunião. Um dos coronéis se desculpou e disse que a função deles ali era checar o que eu queria fazer. Em vários momentos, eles passavam uns para os outros uma pasta que parecia conter informações a meu respeito, embora eu não possa afirmar isso, categoricamente. Em um dado momento, um dos coronéis me perguntou quem havia me indicado para o comandante e, quando soube o nome da pessoa, disse: "Ah, tá!", com clara aprovação. Era como se ele quisesse saber quem era meu "padrinho" para o acesso.

Ao ver como a situação estava se configurando, Aroldo pediu para que todos se calassem e me disse: "Sua proposta de pesquisa é muito interessante e nossa organização é sempre muito aberta. A pesquisa do senhor está aceita". Essa fala contradiz com tudo que ouvi das diversas pessoas que conversei e que trabalham em pesquisa a respeito de forças de segurança. Todos esses haviam dito ter dificuldades imensas para coletar dados. Por sua vez, os agentes da força de segurança com quem conversei se diziam muito frustrados com o fato de que pesquisadores que analisam as forças sempre o fazem de maneira crítica, expondo os problemas ao invés de mostrar as virtudes. Eu sentia, ainda, que, na conversa dos coronéis, eles queriam mostrar que sabiam o que era a verdadeira ciência e minha proposta era bastante decepcionante ao não reforçar as ideias préconcebidas dos coronéis ao respeito do trabalho acadêmico.

Quando Aroldo concedeu o acordo para a pesquisa, nós passamos a discutir qual unidade eu iria analisar. Eu tentei deixar claro que não iria fazer uma avaliação ou julgamento da gestão na FSMB, mas o tempo todo, 
os agentes se referiam a minha pesquisa como "avaliação". Foi ponderado que eu deveria ir onde está a maioria das atividades cotidianas na FSMB, e não em seus esquadrões de elite. Ao final da reunião, o major Moreira, que foi designado como aquele que iria cuidar do meu acesso para a pesquisa, caminhou comigo até a saída do Quartel, por ordem de Aroldo. Ele me disse que eram muito abertos à pesquisa e que me aconselhava a começar visitando as escolas de formação de soldados, sargentos e oficiais. A ideia era que eu ficaria alguns dias em cada uma delas. Despedimos-nos e eu fiquei bastante ressabiado. Sabia que a FSMB era muito refratária a pesquisadores externos e que eu havia exagerado um pouco nas minhas respostas agressivas a uma parte da cúpula da organização. Senti-me bastante incomodado com a abertura do acesso daquela forma.

Não deu outra. Marquei três reuniões com o Moreira, as quais foram desmarcadas em cima da hora. Eu enviei alguns e-mails que ficaram sem resposta. Um deles foi respondido algumas semanas depois e ele me disse que eu poderia ir visitar as escolas. Quando falei com as pessoas designadas na escola, elas começaram a pedir uma série de documentos meus, inclusive, uma carta do líder da minha organização atestando que eu era professor e pesquisador de lá e que estava de acordo com a pesquisa. Segundo o meu contato em uma das escolas, em uma conversa telefônica, o Major Moreira havia pedido que eles me solicitassem a documentação, o que ele poderia ter me pedido logo quando o acesso foi dado pelo Aroldo.

Passaram-se meses após o aceite formal do acesso para minha pesquisa e eu não havia obtido acesso ao campo. Cada vez que eu tentava ir para o campo, alguma dificuldade era encontrada e o início da pesquisa era adiado. Moreira me disse que havia outro professor de uma escola de administração fazendo pesquisa lá. Por coincidência, conhecia o professor. Quando conversamos, ele me disse: "estou há quatro anos tentando ter acesso aos dados. Eles sempre arrumam um empecilho ou um problema. Já me deram algo, mas tem que suar muito. Eu não desisti, mas se prepare para esperar e tenha paciência". Recentemente, encontrei novamente com esse professor que me disse que os questionários foram enviados para ele, mas que não sabia se esses foram, de fato, preenchidos por agentes da FSMB, pois foram enviados por aqueles que ocupam o topo da organização. Suspeitamos que, no mínimo, os questionários foram revisados antes de serem entregues ao pesquisador. Em conversa com um tenente da FSMB, em um evento sobre segurança, ele me disse que, de fato, a força é muito refratária a pesquisadores externos. Comentou ainda que isso sempre é muito difícil e eles fazem o possível para ter controle do que está sendo pesquisado, por medo de "expor a tropa". Quando contei a respeito do Moreira, o tenente retrucou: "Sim, professor. Eles mandaram o senhor para o cão de guarda. Desse mato não ia sair coelho não, ainda mais em uma pesquisa sem que eles consigam controlar". 
$\mathrm{Na}$ mesma época em que eu tentava fazer com que o acesso formalmente garantido pelo comandante, de fato, se configurasse em minha ida ao campo, começou a haver ataques contra as Forças de Segurança na cidade onde eu iria realizar minha pesquisa. Vários agentes foram executados e o clima era de imensa tensão. Todos os amigos e colegas de trabalho diziam que eu deveria desistir da ideia de ir a campo naquele momento, pois seria um risco muito grande para a minha segurança. Além disso, da última vez em que ataques similares aconteceram, inúmeras pessoas inocentes e sem antecedentes criminais foram mortas em uma clara vingança pelo assassinato dos agentes.

Nessa época, fui a um evento em que inúmeros oficiais da FSMB se encontravam presentes. Todos uniformizados. É incrível como estar sem uniforme em um ambiente onde a grande maioria está uniformizada exclui você do grupo, já visualmente. Nesse evento, encontrei o Major Moreira que, parecendo bastante assustado quando me viu, reafirmou que eu iria fazer a pesquisa e que eles eram muito abertos a pesquisadores. Cada vez mais, aumentava a minha impressão de que Moreira fora designado para ter um ambíguo papel de reassegurar o acesso ao campo, mas nunca permitir que ele, de fato, acontecesse. Soube, ainda, que o subcomandante que me atendera estava muito próximo de ir para a reserva e não possuía mais tanta importância nos jogos políticos da FSMB. Ainda no evento, escutei a conversa de vários oficiais dizendo que os ataques contra as forças de segurança haviam colocado suas forças no limite, que vários policiais estavam sem folga e de prontidão, e que o clima dos quartéis não era dos melhores. Dizia-se, ainda, que todos os funcionários da administração foram mandados para a rua e que estavam no limite da operação. Dentro desse contexto, não parecia prudente insistir em ir para o campo. A situação se desenvolveu, todo o comando da FSMB foi trocado e o Major Moreira não ocupava mais a posição na hierarquia que possibilitaria me franquear acesso ao campo. Diante de toda essa situação, decidi-me por desistir da pesquisa e migrar para outra instituição ligada a segurança, onde estou realizando uma pesquisa etnográfica.

\section{Etnografias Fracassadas: Identidades e Contextos na Possibilidade de Acesso ao Campo}

Conforme vimos na primeira parte deste artigo, a questão do acesso ao campo, na literatura a respeito de etnografia na área de administração, é majoritariamente tratada como uma questão prática desse tipo de pesquisa que tende a ser lidada no cotidiano do campo por um pesquisador que possui as "habilidades de gestão adequadas". Aspectos levantados na literatura estiveram presentes nas duas tentativas descritas para se conseguir acesso para se pesquisar organizações. No primeiro caso, eu usei, ativamente, a questão do gerenciamento de impressões no 
campo (JOHNSON, 1975; AGAR, 1980; FETTERMAN, 1989; SILVERMAN, 1999; HAMMERSLEY; ATKINSON, 1995; FELDMAN et al., 2002), com o uso de nomes de instituições reconhecidas e o destaque de características minhas desejadas pelos executivos da empresa a ser pesquisada. No segundo caso, o uso das minhas redes de relações pessoais (AGAR, 1980; BRYMAN, 1988; HAMMERSLEY; ATKINSON, 1995; GILL; JOHNSON, 2002) desempenhou papel preponderante para conseguir chegar até uma reunião com a cúpula da FSMB. Também se mostrou fundamental a reputação da instituição em que trabalhava no momento de se conseguir o acesso ao campo. Nos dois casos, não deixar claramente explícito o que se ia pesquisar (JOHNSON, 1975; HAMMERSLEY; ATKINSON, 1995; ALVESSON; DEETZ, 2000) fez parte do processo. Porém, as reações foram diferentes.

No jornal, o fato de não deixar o foco da pesquisa explícito não gerou quaisquer dificuldades; já no caso da FSMB, esse foi um ponto de tensão no encontro formal para se decidir o acesso do pesquisador à organização. Buscar desenvolver e nutrir relacionamentos com atores importantes do campo (BRYMAN, 1988; FETTERMAN, 1989; FELDMAN et al., 2002) foi algo que tentei fazer de forma mais clara no caso do jornal. Tal estratégia foi útil para lidar com os executivos da empresa, mas se mostrou pouco útil na relação com os operários no chão de fábrica. Ainda no caso do jornal, ficou explícito que os "leões de chácara organizacionais" (MORRILL et al., 1999), que franqueiam ou não o acesso ao campo, não estão apenas na alta cúpula da organização. A dificuldade de até mesmo conversar com alguns faxineiros no chão de fábrica deixa isso evidente. No caso da FSMB, os atores importantes, embora, na maior parte das vezes, corteses, ao que tudo indica, eram aqueles que não queriam a minha presença na organização.

Os dois fracassos ao se tentar realizar as etnografias organizacionais descritos acima mostram que a questão de negociação de acesso com a cúpula da organização é apenas parte do problema relacionado com as possibilidades de se coletar ou não dados em organizações, e que a "gestão do cotidiano no campo" não está restrita, exclusivamente, às ações e às habilidades pessoais dos pesquisadores. Os casos mostram que há, pelo menos, duas outras dimensões a se levar em conta quando falamos da possibilidade de se conseguir acesso para realizar etnografias organizacionais. A primeira delas está relacionada com o modo pelo qual a identidade do pesquisador é construída no dia a dia da pesquisa. A segunda diz respeito ao contexto social em que a organização a ser pesquisada compartilha e constrói.

Ao desenvolver este artigo, parti da visão de que a identidade é socialmente construída em contextos organizacionais (GERGEN, 1991; PULLEN; LINSTEAD, 2005). Ainda, discuti que identidades particulares dos pesquisadores podem limitar ou determinar aquilo que o pesquisador pode conseguir no campo (WAX, 1979). Porém, diferentemente de Wax 
(1979), que percebe a identidade como um atributo natural do pesquisador e algo que está sob seu controle, eu tinha uma percepção da identidade como socialmente construída em cada contexto organizacional. Essa visão a respeito da construção da identidade me possibilitou dar sentido ao que vivenciei no campo. Conforme expus acima, no caso do jornal, duas identidades foram construídas no contato com o campo. Para conseguir conversar com os executivos da corporação, o professor da instituição de ensino superior de renome, com experiência de vivência em gráfica de jornal de destaque internacional foi uma identidade que eu procurei desempenhar e que foi facilmente aceita e reforçada em minhas conversas com os executivos, facilitando o meu contato e o acesso. Dentro do mesmo jornal, o professor transformou-se em um "playboy" quando em interação com os operários do chão de fábrica. As falas, os gestos, as similaridades do pesquisador de campo com os superiores dos operários fez com que esse fosse percebido como alguém da elite e, portanto, não confiável. Ambas as visões a meu respeito possuem semelhança com atributos meus e eu não tive quase controle sobre o modo como aspectos da minha identidade foram engajados pelas pessoas com quem interagi nas organizações nas quais tentei pesquisar.

No caso da FSMB, mesmo vindo de uma instituição nitidamente admirada pelos oficiais com quem conversei, o tipo de pesquisa que eu propus realizar não correspondia com a imagem que eles possuíam do que seria uma pesquisa "científica". Com isso, a minha proposta de pesquisa valeu mais do que a instituição de onde eu vinha para ser visto como alguém que não poderia passar pelos muito bem vigiados portões da organização militar. Talvez, se eu, ou qualquer parente meu, tivesse pertencido à $\mathrm{FSMB}$, o contato poderia ter sido facilitado. Além disso, como eu tive relatos de que o acesso à pesquisa a esse tipo de organização é sempre difícil, por se tratar de uma instituição que aparenta ser avessa ao escrutínio público, a construção da minha identidade como alguém que não faz ciência e, portanto, não pode pesquisar, tem ainda uma dimensão política de me excluir da organização.

Assim, a possibilidade da construção da identidade do pesquisador no campo não está única e exclusivamente centrada no pesquisador, não sendo um atributo natural e imanente do mesmo. O que os dois casos nos mostram é que a identidade que será construída depende de como os demais agentes do campo irão interagir e engajar com certos atributos do pesquisador, reforçando alguns aspectos ou tirando ênfase de outros. O pesquisador pode, em alguns momentos, ser constituído como um professor com experiência internacional e, em outros, como um playboy, isso tudo dentro da mesma organização, conforme vimos acima. Em outro contexto organizacional, o professor pesquisador da instituição de ensino de prestígio pode ser construído como alguém que realiza um trabalho não científico. E estamos aqui, sempre falando da mesma pessoa, que trabalhava na mesma instituição, no caso das duas pesquisas. Tais 
constituições de identidade do pesquisador estão relacionadas com as consequências políticas de se conseguir ou não se conseguir acesso para fazer pesquisa. Ainda, essas estão ligadas à possibilidade de inclusão ou de exclusão do pesquisador na organização, relacionando-se, assim, com as possibilidades de as portas das organizações se abrirem ou se fecharem.

Os casos apresentados mostram, ainda, um segundo aspecto que merece atenção nas possibilidades de se ter sucesso ou fracasso para se conseguir acesso para a realização de pesquisa organizacional etnográfica. Aqui me refiro à questão do contexto que constrói a organização e que também é construído por ela. No caso do jornal, trata-se da questão de desigualdades sociais no Brasil, reconhecidamente, uma das maiores do mundo. A desigualdade social brasileira era refeita cotidianamente dentro do jornal. Executivos ganhavam muito mais e possuíam maiores privilégios do que os operários. Executivos não usavam uniformes, ao passo que os operários o faziam, deixando nítido quem era quem. Executivos iam para o trabalho em carros caros, ao passo que os operários iam de moto ou transporte coletivo, e por aí a fora. A questão da desigualdade também criou claras barreiras ao acesso de informações no campo. O pesquisador, que gostaria de estudar estratégias de resistência dos operários, foi ironicamente ele próprio vítima de resistência por parte dos trabalhadores. Essa resistência se mostrou ora cordial e cínica, ora agressiva e ameaçadora. Transpor a barreira da desigualdade configurouse com um problema central da possibilidade de ter um acesso mais profundo no campo. A questão do cansaço do pesquisador também afetou a sua condição de fazer pesquisa.

No caso da FSMB, o papel do contexto assumiu cores mais fortes. A organização em questão já era reconhecida pelas pessoas como sendo um lugar violento e em constante interação com a violência, tanto como uma força que tenta combater a violência, bem como uma força que pratica atos violentos. Isso estava claramente demonstrado nas falas que tentavam persuadir o pesquisador a não prosseguir sua pesquisa. $O$ fato de ela estar sendo vítima de ataques articulados por facções criminosas e as consequências que tais ataques tiveram na força de segurança, com a perda de credibilidade do comando que foi substituído, indica que certas organizações têm a possibilidade de deixar o pesquisador altamente vulnerável. O fato de a FSBM existir para lidar com a violência e a criminalidade sugere, ainda, uma organização desconfiada de agentes externos independentes.

Nos dois casos aqui analisados, uma primeira indagação é: o que tais organizações ou grupos dentro da organização praticam ou acreditam que praticam que não pode ser revelado? Um segundo aspecto interessante é o fato de que os dois casos chamam atenção para mecanismos presentes em organizações que buscam excluir a possibilidade da pesquisa etnográfica. De modo amplo, podemos falar de estratégias de resistência contra os pesquisadores ligadas à construção de identidades dos pesquisadores em 
ação, e também, a aspectos contextuais da organização. Por fim, vale destacar que o contexto da organização acaba por ajudar ou atrapalhar a possibilidade de se realizar pesquisa etnográfica em organizações.

\section{Conclusão}

Este artigo analisou duas tentativas para se conseguir acesso para realizar etnografias dentro de diferentes organizações no Brasil. As organizações analisadas foram um jornal e uma força de segurança. Nos dois casos, as pesquisas fracassaram em virtude de dificuldades de acessar informações no campo. Utilizando uma narrativa confessional, discuti que aspectos ligados à construção da identidade do pesquisador durante a pesquisa e o contexto da organização a ser analisada atuaram de forma a impossibilitar a plena realização das pesquisas pretendidas. É possível argumentar que eu, enquanto pesquisador, não agi corretamente, nos casos descritos. Assim, pretendi neste texto fazer menos um julgamento retrospectivo do que fiz e mais trazer à tona as dificuldades que podemos encontrar na prática da pesquisa etnográfica. Especificamente, discuti como as tentativas de se conseguir acesso para a realização de pesquisas etnográficas dependem do contexto social em que a organização está inserida, aspecto desconsiderado pela literatura, e também como as dinâmicas de campo terminaram por constituir identidades específicas dos etnógrafos em ação no campo e que tais identidades facilitam ou dificultam a realização da pesquisa. Esses dois aspectos foram muito pouco abordados pelas discussões a respeito de acesso e etnografia organizacional pela literatura, que é, em sua maioria, Anglo-Saxã. Discuti, ainda, que o acesso formal é apenas uma das etapas para se conseguir coletar informações no campo.

Ao fazer isso, procurei contribuir para discussões a respeito das práticas de acesso ao campo no Brasil, uma vez que a maioria da literatura disponível a respeito do assunto está escrita em inglês e trata do assunto exclusivamente no exterior. Além disso, no Brasil, temos o costume de apresentar pesquisas que representam os casos de sucesso e não revelamos nossos fracassos como pesquisadores, deixando de aprender com eles. Considero fundamental que os casos de fracassos sejam discutidos para podermos desconstruir a imagem de que pesquisadores não erram e, também, para podermos compartilhar nossas angústias ao realizar pesquisas, algo que ainda fazemos muito pouco, talvez para preservar uma imagem de que somos quase super-heróis no campo. A discussão acima mostrou que o acesso não depende apenas das habilidades do pesquisador, mas, também, de construções indentitárias e do contexto em que a organização está inserida, dois aspectos não abordados pela literatura. Discuti, ainda, que o pesquisador pode enfrentar severas resistências no campo para fazer pesquisa. 
Temos o costume de discutir a resistência das pessoas que trabalham na empresa, mas discutimos pouco as resistências contra os pesquisadores, o que sugere a necessidade de desenvolver novos estudos sobre o tema e, também, indicar que a posição de condução de pesquisa é uma posição de poder que precisa ser problematizada. Os casos apresentados aqui mostram que fazer etnografia pode ser danoso para a carreira do pesquisador em uma academia dominada pelo produtivismo. Etnografia organizacional requer tempo, energia, faz o pesquisador passar por inúmeras inseguranças, e, ainda, ela pode não dar certo, como mostrei aqui. Todavia, é a melhor forma de conhecer as organizações como elas acontecem, com rigor de detalhes e minúcias. Fazer etnografia, além de ser altamente prazeroso e útil para o campo, em uma academia dominada pelo produtivismo, é, antes de qualquer coisa, uma prática de resistência acadêmica.

\section{Referências}

ALCADIPANI, R.; HODGSON, D. By any means necessary? Ethnographic access, ethics and the critical researcher. Tamara: Journal of Critical Postmodern Organization Science, v. 7, p. 127-146, 2009.

ANDERSEN, I. B.; BORUM, F.; KRISTENSEN, P.; KARNOE, P. On the art of doing field studies. Munksgaard: Handelshojskolens Forlag, 1999.

BATE, S. Whatever happened to organizational anthropology? A review of the field of Organizational Ethnography and Anthropological Studies. Human Relations, v. 50, p. 1147-1175, 1997.

BELL, E.; BRYMAN, A. The ethics of management research: an exploratory content analysis. British: Journal of Management, v. 17, p. 113, 2006.

BROWN, P.; MONTHOUX, G.; MCCULLOUGH, A. The access casebook. Stockholm: Teknisk Högskolelitteratur, 1976.

BRUNI, A. Access as trajectory: entering the field in organizational ethnography. In: Paper presented at the annual meeting of EGOS Colloquium, 6-8 July, Bergen, 2006.

BRYMAN, A. Ethnography: ethnographic fieldwork practice. Thousand Oaks, vol.4, London: Sage, 2001.

BUCHANAN, D.; BODDY, D.; MCCALMAN, J. Getting in, Getting on, and getting back. In: BRYMAN, A. Doing Research in Organizations. London: Routledge, 1988. 
CALVEY, D. Getting on the door and staying there: a cover participation observational study of bouncers. In: LEE-TREWEEK, G.; LINKGOLE, S. Danger in the field: risk and ethics in social research. London: Routledge, 2000.

CAVEDON, N. "De frente pro crime": cultura organizacional e socialização dos peritos ingressantes no Departamento de Criminalística do Instituto-Geral de Perícias do Rio Grande do Sul. Revista de Administração Mackenzie, v. 11, n. 4, p. 38-65, 2010.

CLIFFORD, J. The predicament of culture: twentieth-century ethnography, literature, and art. Cambridge: Harvard University Press, 1988.

CLIFFORD, J.; MARCUS, G. Writing culture: the poetics and politics of ethnography. London: University of California Press, 1986.

CROWLEY, J. E. Friend or Foe? self-expansion, stigmatized groups, and the researcher- participant relationship. Journal of Contemporary Ethnography, v. 36, n. 6, p. 603-630, 2007.

DENZIN, N. K. Interpretive Ethnography: ethnographic practices for the

21st century. Thousand Oaks, CA: Sage Publications, 1997.

EMERSON, R.; FRETZ, R.; SHAW, L. Writing ethnographic fieldnotes. Chicago: University of Chicago Press, 1995.

FELDMAN, M.; BELL, J.; BERGER, M. Gaining access: a practical and theoretical guide for qualitative research. Walnut Creek: Altamira Press, 2002.

FETTERMAN, D. Ethnography step by step. London: Sage, 1989.

GELLNER, D.; HIRSCH, E. Organizations: anthropologists at work. Oxford, New York: Berg Publications, 2001.

GILL, J.; JOHNSON, P. Research methods for managers. London: Paul Chapman, 2002.

GRAY, P. S. Exchange and access in field work. Urban Life, v. 9, n. 3, p. 309-331, 1980.

GUMMESSON, E. Qualitative methods in management. London: Sage, 2000. 
HAMMERSLEY, M.; ATKINSON, P. Ethnography: principles in practice. New York: Routledge, 1995.

HARRINGTON, B. The social psychology of access in ethnographic research. Journal of Contemporary Ethnography, v. 32, p. 592-565, 2003.

JAIME, P. Um texto, múltiplas interpretações: antropologia hermenêutica e cultura organizacional. RAE-Revista de Administração de Empresas, v. 42, 4, p. 72-83, 2002.

JOHNSON, J. Doing field research. New York: The Free Press, 1975.

JONES, T. Ethnography, belief ascription, and epistemological barriers. Human Relations, v. 53, p. 299-310, 2000.

KUNDA, G. Engineering culture: control and commitment on a hightechnology firm. Philadelphia: Temple University Press, 1992.

MASCARENHAS, A. O. Etnografia e cultura organizacional: uma contribuição da antropologia à Administração de Empresas. Revista de Administração de Empresas, v. 42, n. 2, p. 88-94, 2002.

MORRILL, C. et al. Toward an organizational perspective on identifying and managing formal gatekeepers. Qualitative Sociology, v. 22, p. 51-72, 1999.

OLIVEIRA, J. S; CAVEDON, N. R. Micropolíticas das práticas coditianas: etnografando uma organização circense. Revista de Administração de Empresas, v. 53, n. 2, p. 156-168, 2013.

PULLEN, A.; LINSTEAD, S. (eds). Organization and Identity. London: Routledge, 2005.

SILVERMAN, D. Doing qualitative research: a critical guide. London: Sage, 1999.

SMITH, V. Ethnography bound: taking stock of organizational case studies. Qualitative Sociology, v. 20, p. 425-35, 1997.

SPRADLEY, J. P. The ethnographic Interview. New York: Holt, Rinehart \& Winston, 1079.

TURETA, C.; ALCADIPANI, R. Entre o observador e o integrante da Escola de Samba: os não-humanos e as transformações durante uma 
pesquisa de campo. Revista de Administração Contemporânea, v. 15, p. 209-227, 2011.

WAX, R. Gender and age in fieldwork and fieldwork education: no good thing is done by any man alone. Social Problems, v. 26, n. 5, p. 509-522, 1979.

VAN MAANEN, J. Tales of the field. London: University of Chicago Press, 1988. 